\title{
Hidden Value: Investigating the Physics Demonstration as Aesthetic Experience
}

\author{
Sydney Seese and Megan Halpern \\ Lyman Briggs College, Michigan State University, East Lansing, MI, 48824
}

Kathleen Hinko

Lyman Briggs College and the Department of Physics and Astronomy, Michigan State University East Lansing, MI, 48824

Physics demonstrations have a rich history both in and outside the classroom. Evaluations of physics demonstrations have traditionally focused on their ability to facilitate comprehension and retention of information; however, John Dewey's theory of aesthetic experience allows us to instead examine them as meaningful interactions between demonstrators and audiences. In this work, we demonstrate the utility of aesthetic experience as a model for science communication by investigating an undergraduate student group that performs physics demonstrations at family science events. Using observations and interviews, we found that the performers were engaged in expressive acts alongside their intention to explain the physics content correctly. Thus, this work shows that the experience model of science communication has the ability to reveal the significance of these demonstrations and also may be applicable to many informal learning and public engagement interventions.

2019 PERC Proceedings edited by Cao, Wolf, and Bennett; Peer-reviewed, doi.org/10.1119/perc.2019.pr.Seese Published by the American Association of Physics Teachers under a Creative Commons Attribution 4.0 license. Further distribution must maintain attribution to the article's authors, cover page, and DOI. 


\section{INTRODUCTION}

Physics demonstrations have long been used in and out of physics classrooms to visually communicate concepts and phenomena. There are a vast number of resources documenting existing and popular demonstrations for many different physics topics, which are available to physics educators and the general public [1]. Many physics departments own significant numbers of demonstrations that have been bought from dedicated demonstration companies or built in house. The organization and upkeep of this equipment is often part of staff or faculty duties [2]. Some physics buildings also showcase corridor demonstrations that allow people to observe physics demonstrations through glass as many times or as long as they want, drawing out the experience and giving the person an element of control (like pushing a button to start a demonstration) [3]. Nationally, the Physics Instructional Resource Association (PIRA) has created a database of over 2500 demonstrations and holds sessions each year at the American Association of Physics Teachers (AAPT) conference [2].

Physics demonstrations are also prevalent in public engagement about physics. One famous example is Richard Feynman demonstrating at a press conference the critical failure of O-rings in the NASA Challenger shuttle disaster [4]. Physicists and other individuals have had popular success centering physics discussions around demonstrations on television or Youtube, such as Dianna Cowern (aka "Physics Girl") [5], and astronauts on the International Space Station [6]. A popular model of physics outreach embraced by physics departments are demonstration presentations, where physicists and physics students go out to the community or into schools and perform exciting demonstrations of physics phenomena. Programs like this are numerous all over the country (examples include the Physics Circus at University of Texas, Little Shop of Physics at Colorado State University, and the Physics Van at University of Illinois). They are also supported by efforts within both the American Physical Society (APS) and AAPT. For example the Office of Public Engagement for APS has put out a resource guide on doing "Physics on the Road" for public audiences [7].

Research on Physics Demonstrations: Despite their ubiquity, the reasons physicists use demonstrations in both formal and informal educational environments are not as straightforward as might be presumed. Much of the research done on physics demonstrations focuses on either understanding and retention or on affect and attitude [8-10] For example, Crouch et al. used polling tools to assess student understanding and examined three different demonstration techniques: observation (which involved no student inquiry), prediction, and discussion (which both involved student predictions before the actual demonstration) [11]. Students who simply observed the demonstration could not explain the physics concepts behind the demonstrations any better than the students who did not see a demonstration at all. Students who were encouraged to predict and discuss the demonstrations ex- plained the physics better than both the control and observation group, but the difference was small. In a different study, Miller et al. conducted multiple choice and short answer surveys at the end of the demonstration and again at the end of the semester [12]. They concluded that it is very important for student understanding that students make predictions before the demonstration takes place, even if the prediction is incorrect. They also emphasized that students need to "correctly observe" the demonstration while it is happening.

Saviez and Shakerin focused on enthusiasm for physics learning [13]. They used interactions with fluid toys to help gauge student understanding of topics in physics relating to liquid, density, gases, and surface tension. They concluded that physics toys like these can be used to engage students and help them to become more enthusiastic about a physics topic. They also give students a medium to better understand their own understanding of physics and voice a physics topic using a concrete example. They suggested that this type of exercise is a more engaging way to understand a student's level of understanding and background than giving a test to assess understanding.

In each of these cases, the findings might not suggest physics demonstrations are vitally important to physics education. When considering the body of work done on demonstrations, we might conclude that though they may shift affect, they do little to increase understanding and retention. But this picture of demonstrations is not representative to the degree to which demonstrations are used and valued in and out of physics classrooms. Put simply, there must be more to demonstrations than this body of research suggests, or they would not play such a prominent role in formal and informal physics education. We assert that thus far, the research has failed to understand the role and value of demonstrations because it has sought to break the demonstration into its constituent parts (emotional response, content understanding, or retention) rather than examining the demonstration as a whole entity. In this paper, we draw on Dewey's theory of aesthetics to examine physics demonstrations holistically, as expressive objects.

\section{DEWEY'S THEORY OF EXPERIENCE}

To understand what happens during physics demonstrations, we draw on Dewey's theory of aesthetic experience [14]. Dewey describes an aesthetic experience, or an experience as something that has a sense of unity to it, and that leaves the person having the experience with a feeling of fulfillment or completion. An experience is significant because it holds meaning. Though meaning is central to Dewey's idea of experience, to suggest that an experience is meaningful is not necessarily to suggest that it is profound. Rather, an experience is rendered meaningful because we draw on our previous experiences as well as our interaction with the object with which we are engaged, and we attach meaning to that moment. Dewey also notes the cumulative 
and contextual nature of experiences: each experience holds a sense of continuity (it is shaped by all previous experiences) and is the result of an interaction with something in the world [15]. Similarly, while Dewey does suggest that these experiences change us, other scholars have attached greater importance to the idea of transformation as a consequence of experience, including physics educational environments [16-18]. However, in our interpretation of Dewey, more central than the notion of transformation in his discussions of experience is the idea that experiences are plentiful and ordinary. Dewey rejects the separation of art from other parts of life, describing the way an argument with a friend or a meal could be an aesthetic experience just as easily as an interaction with a work of art.

Physics Demonstrations as Expressive Objects: Dewey further describes the kinds of objects with which one has an experience as expressive objects, which are created through acts of expression. When someone has an encounter with an expressive object, they may (or may not) have an experience. For Dewey, expressive objects are not separate from the acts by which they were created, nor are experiences with these objects fully contained within the individuals having the experiences; rather they are an interaction between objects and the individual.

By re-characterizing physics demonstrations as objects of expression, we can unlock the value they have in informal physics education, revealing new opportunities for evaluation and development of demonstrations. This means demonstrations are connected to the process by which the demonstrators developed and performed them, but they are also subject to the processes by which audience members interpret and make meaning of them. They should be viewed, then, as links between the demonstrators and audiences that hold varied meanings for both. Rather than considering whether demonstrations are transformational or seeking evidence of their impact, then, researchers in informal physics education might benefit from seeking to understand the processes by which demonstrations are developed as acts of expression as well as the interactions presenters and audiences have with these expressive objects.

This paper is part of a larger research project $[19,20]$ to use Dewey's theories of experience and expression to develop new design and evaluation processes for informal science learning. In this pilot study of a group of undergraduate science students who develop and perform physics demonstrations, we use ethnographic observation and interviews to better understand demonstrations as objects of expression.

\section{METHODS}

The student group, which has approximately 30 members from various colleges and departments at a major university, has existed for 28 years. They conduct demonstrations in many contexts, such as elementary, middle, and high schools, special events, and local cultural centers like museums and churches. For this pilot study, we observed seven events, each hosted by between three and six students, in four different environments. During each event, the group would perform several demonstrations and invite audiences to participate in several hands-on activities. The first event we observed was at church event; the second, science night at an elementary school; followed by three events held throughout "Physics and Astronomy Day" at a local science center, and two events at the University's annual science festival. In addition to these observations, we conducted 12 interviews with presenters (pseudonyms are used below). Each interview was conducted after the event and lasted between 15 and 30 minutes. We also attempted to interview and obtain artifacts from audiences who had observed the demonstrations but collection proved difficult, and we did not collect enough data to reliably analyze.

We then used qualitative software (Atlas.ti) to analyze our data, which included field notes from our observations, photographs, videos of demonstrations, and audio recordings of interviews with demonstrators. The first author began by using open coding to analyse a subset of the interviews. The same author then re-coded these interviews, followed by the second author. These two passes helped refine initial codes and documented emergent themes and the relationships between them. After all three authors discussed the results, the first author then continued coding the interviews and the recordings and observations of the demonstrations. All three authors then discussed final codes and themes.

\section{FINDINGS}

We found that two particular demonstrations were especially important to the demonstrators that we spoke with. The group referred to these as "Marshmallow Smashies" and "Bernoulli's Principle". Marshmallow Smashies is an example of a "hands on" activity, which interviewees distinguished from more performative demonstrations which they called "stage show." It is a variation of demonstration that illustrates the effects of air pressure by putting an object inside a glass container, evacuating the container with a pump, and observing what happens to the object while air is being removed and after air is let back in. In this version, the demonstrators added an interactive component by using marshmallows they had asked participants to decorate with faces. We observed the demonstration during science night at an elementary school, where families gathered and participated in the activity together. We also observed several groups present Bernoulli's Principle, a demonstration that shows that faster moving air passed over top of an object will reduce the air pressure above it, resulting in the upward rise of the object from unbalanced forces. The group describes this demonstration as a stage show and uses a leaf blower to levitate objects such as a beach ball. It was part of their repertoire at the church event, the physics and astronomy day event, and the 
science festival event.

For this paper, we draw primarily on our ethnographic observations. To capture the richness of these demonstrations as expressive objects, we provide excerpts from what Geertz calls thick description of the events [21]. These narrative accounts (see Figure 1) provide not only an account of what happened, but also provide background and context. Additionally, thick descriptions are imbued with the ethnographer's interpretations of meanings. Such a methodology has long been an important part of anthropological research, but may be new to physics education research. We suggest ethnographies and thick descriptions can be employed to help develop new ways of measuring the success of demonstrations and of informal science learning.

\section{DISCUSSION}

What we see in these thick descriptions illustrates Dewey's theory well: the expressive objects (the demonstrations) cannot be broken into their constituent parts; there is no list of criteria or outcomes that we can predict or describe. Further, we cannot break apart emotion, interaction, and knowledge. Instead, we can see the connections both between the presenters and their demonstrations and between the demonstrations and the audiences. These connective tissues are where we find meaning in science demonstrations. They neither simply excite audiences nor do they merely transmit information for understanding and later recall. Instead they are made up of moments, potentially aesthetic experiences, for both presenters and audience members, that are greater than the sum of the parts that can be identified using metrics of understanding and are richer than a simple emotive state, like excitement.

To analyze or evaluate these expressive objects, we can describe them in terms of their relationships to presenters and audiences. The thick description, as well as our interviews, reveal that the demonstrator made aesthetic decisions based on the objects, environment, and audience. Several presenters noted that Marshmallow Smashies was their favorite demonstration. Lilly suggested this was her favorite because it has "a 'Wow'-Factor" and is "very visually engaging which is so important, especially with younger audiences..." She went on to note that this is a demonstration that gets one of the largest reactions from the audience, which she finds exciting. Polly reflected on what the demonstration allowed her to do: "I am definitely the type of person, I like to do as much movement as possible and things as dramatically as possible. And I have this way that I do Marshmallow Smashies that is very big and loud and kids always love it." Their enthusiasm for Marshmallow Smashies is tied to their own experiences, as well as the way they perceive their audiences to experience it. Polly notes that the demonstration is suited to her personality and describes the way she expresses herself with the audience.

In presenters' accounts of the demonstrations, we also find evidence of audience members' experiences, and their relationship to the expressive objects. Sully describes one par- ticular presentation of Marshmallow Smashies as his favorite demonstration experience because, "as I was starting the explanation after the fact the kid actually finished it." At first glance, it might seem this is a moment of straightforward understanding, and that Sully's personal triumph stemmed from the audience member's ability to grasp the physics behind the demonstration. However, we suggest that the interaction transcended straightforward understanding. The child who finished Sully's sentence was moved to do so not just because she or he understood, but because that understanding held meaning. Though it isn't possible to know what was inside the child's mind, one could easily imagine that interaction was evidence of an aesthetic experience. The moment when the child spoke up was the moment they felt a sense of wholeness within the event, when the culmination of the expressive object sparked delight or satisfaction with the interaction.

In each demonstration of Bernoulli's Principle, the audience visibly and audibly reacts to the moments in which they've been asked to make a hypothesis, and subsequently are proven wrong. As Billy notes, "what sparks the most interest in the kids is when things go against their expectations." All of the demonstrators consistently encourage these "wrong" predictions and capitalize on the unexpected results. Sally also emphasizes the strangeness of the results, noting that she likes to say, "look how weird this thing that's going on actually is. Like, the beach ball is floating because the air [is flowing] above, not below, like it's not pushing up from above, it's the air pressure is supporting it. That's just crazy to me when I think about it!" By reflecting her own surprise and wonder about the outcome of Bernoulli's Principle, she is drawing on her own prior experiences and allowing them to shape the expressive object. The audience is able to respond with surprise and to revel in the unexpected. This, again shows evidence of audience experiences with expressive objects. It also shows how the presenter is connected to the expressive object and to the audience experience. Her explanation is not simply an explanation of a principle, but is an expression of her experiences.

\section{IMPLICATIONS}

Our observations revealed that whether or not audiences understood the physical properties of the vacuum was largely beside the point, while any description of their emotions, including excitement, about the demonstration failed to capture what was happening. Instead, we find a co-mingling of emotion, interaction with the world (the object), reflection, and meaning making on both the part of the demonstrators and the audiences. For example, during Bernoulli's Principle, we cannot separate the knowing looks presenters give to suggest that what's going to happen is not what the audience thinks. They see that not only do marshmallows expand, but the faces children drew on them expand along, and that different audience members see and call out different aspects of the phenomenon, further shaping each others' potential experiences. 


\section{MARSHMALLOW SMASHIES}

"So, what we have here guys, is what's called a vacuum chamber. And this vacuum chamber is hooked up to this, " he lays his hand on the mysterious machine, "which is a vacuum. Do you all know what vacuums are?"

"Yes," reply the more brave viewers.

"What do vacuums do?" He asks

"Suck," says the frontmost viewer. Looking around at his peers they nod slowly, "yeah, suck" says another student.

"They suck up stuff!" Repeats the demonstrator; "We're going to use this vacuum to suck all the air out of this container." He pats the chamber beneath his hands, "So if we suck all the air out from around the marshmallows, what do you think might happen to the marshmallows?"

"They'll float!" the frontmost viewer replies confidently.

"You think it'll float? Interesting, do you have a hypothesis?" He turns to the other viewers.

"They'll shrink!" Calls out one viewer "They'll get sucked into the vacuum!" proclaims another.

"Alright... You ready to see this?" The demonstrator asks. More people have gathered around the table now, craning their necks to see what will happen. The parents further back lean forward, I find myself completely certain what will happen, but eager to see myself proved right. We all seem to hold our breath.

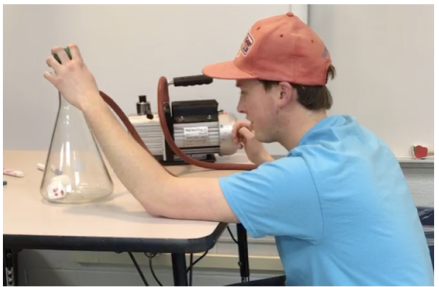

"Three, two, one!" He flips the switch on the vacuum. Scribbles grow before our eyes. A combination of gasps, one of them my own. exclamations of joy, and shocked looks back at parents come from the audience.

"Ooh! They're gonna pop!' Squeals the frontmost viewer. "Ooh they're getting BIG" giggles another. The demonstrator smiles conspiratorially at the audience And switches the machine off. Quiet fills the air and he quickly puts his hand on the ball blocking the top, glances around, and rips the ball out.
There is a loud whoosh sound and the inflated characters inside the tube suck back in on themselves even smaller than what they were before the demo. The cries are even louder this time as people laugh, squeal, and gasp again. He upturns the bottle and presents the shrunken works of art to their creators.

"So what happened?" He asks the audience. But his question is overshadowed by the students statements, "Ooh they're cute!"

"Can we feel them?"

"Ooh his teeth are bad now."

"So what happened," the demonstrator continues, "was the air got sucked up, and that's why the marshmallow got bigger," he reaches his arms out like he's stretching,

"because the air inside the marshmallow was pushing out," he spreads his fingers. "But then when all the air was gone, I stopped the vacuum and I took the ball off, you heard the whooshing noise, right?"

"Yeah," "yes"

"All the air around us was going back into the chamber and crushed the marshmallows," he pulls his body together into a cramped position, "and so that's why they got all wrinkly."

"And SMALL" said the frontmost viewer,

"Yep" the demonstrator replies.

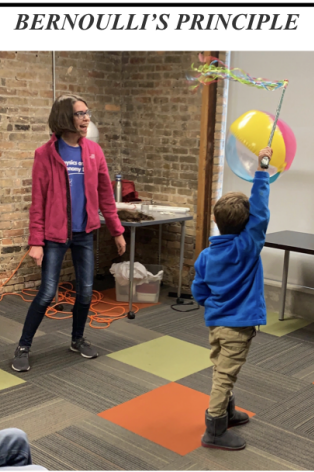

"This," the demonstrator calls out while turning and showing the pole to the audience, "is the Magical Wand of Science," turning back to his chosen volunteer he cries out, "I will give you this magic wand of science to give you the magic powers you need to do the experiment." The volunteer smiles and takes the wand from him as the audience whispers excitedly about the magic they're about to see.

"Here we have a leaf blower which blows air, and today we want to get this beach ball to float Now if we want to use the air from the leaf blower

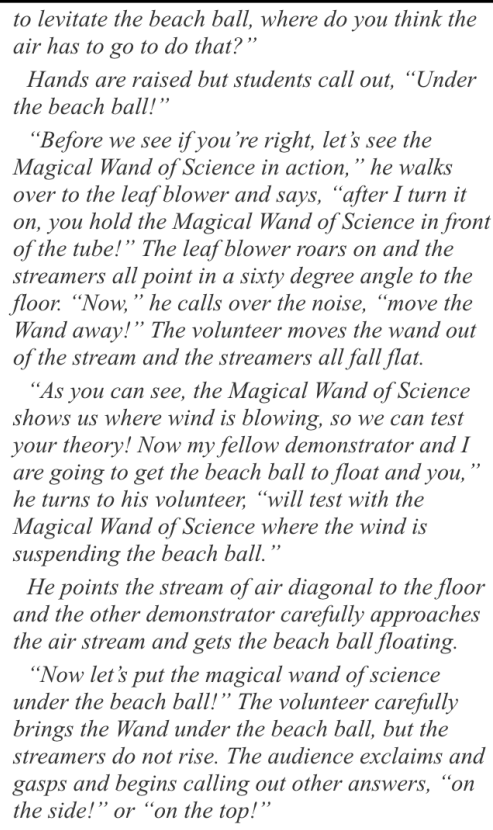

Hands are raised but students call out, "Under the beach ball!"

"Before we see if you're right, let's see the Magical Wand of Science in action," he walks over to the leaf blower and says, "after I turn it on, you hold the Magical Wand of Science in front of the tube!" The leaf blower roars on and the streamers all point in a sixty degree angle to the floor. "Now," he calls over the noise, "move the Wand away!" The volunteer moves the wand out of the stream and the streamers all fall flat.

"As you can see, the Magical Wand of Science shows us where wind is blowing, so we can test your theory! Now my fellow demonstrator and I are going to get the beach ball to float and you," he turns to his volunteer, "will test with the Magical Wand of Science where the wind is suspending the beach ball."

He points the stream of air diagonal to the floor and the other demonstrator carefully approaches the air stream and gets the beach ball floating

"Now let's put the magical wand of science under the beach ball!" The volunteer carefull brings the Wand under the beach ball, but the streamers do not rise. The audience exclaims and gasps and begins calling out other answers, "on the side!" or "on the top!"

"Let's try those new hypotheses out!" He smiles and nods to the volunteer. She tries on the side of the beach ball to no avail, and I watch confused as she brings the Wand over the top. Suddenly the streamers whip over the ball, following its curve. The audience exclaims joyously at finally finding the source.

"Why do you think that happens?" He looks to the audience.

"The spinning of the ball keeps it floating!"

"The air flows around it!"

"Right now we're all getting crushed by air," he says dramatically. "When the blower makes the ball float, it's doing so, like we proved, by blowing air over the ball. It dispels the pressure on top of the ball by the air that is crushing us all the time, and allows the ball to float! We call that Bernoulli's Principle"

"To show you how powerful this principle is, we're going to show you all you need to make this work is for part of the object to be round." The helping demonstrator pulls out a large water bottle with a rounded end. The audience again exclaims as we watch the demonstrators attempt to get the water bottle to float, it takes a couple of tries, but sure enough when the air hits the bottle right, it suspends it.

"Wow," whispers the audience member beside me

FIG. 1. Thick descriptions of the Marshmallow Smashies and Bernoulli's Principle demonstrations.

The value of reimagining the way we describe demonstrations through the lens of Dewey's theory is that we can open up new ways of explaining and valuing what happens in demonstrations. This paper suggests the need for a new language by which we can speak about demonstrations as expressive objects that are imbued with meanings. Those meanings will not be identical for each of the presenters or participants involved, but meaning is tied to the expressive act and it expresses something about the world.
In this paper, we have suggested, using Dewey's theory of experience, that physics demonstrations are expressive objects. This recharacterization provides a first step toward a theory of informal science education as experience. Practically, because our analysis drew heavily on our thick descriptions as well as our interviews, we suggest these research methods are invaluable in revealing the meanings imbued in expressive objects. This work is supported by a Michigan State University S3 Grant. 
[1] R. E. Berg, Resource Letter PhD-2: Physics Demonstrations. American Journal of Physics, 80(3), 181-191 (2012).

[2] http://physicslearning.colorado.edu/PiraHome or http:// www.pira-online.org, The PIRA Home Page, with links to the PIRA DCS, the PIRA 200, and the PIRA Demonstration Bibliography.

[3] W. A. Hilton, Demonstrations as an aid in the teaching of physics. The Physics Teacher 19, 389 (1981).

[4] R. Feltman, A famous physicist's simple experiment showed the inevitability of the Challenger disaster, Washington Post, Jan. 27, 2016.

[5] https://www.youtube.com/channel/UC7DdEm33SyaTDtWYGO2CwdA, Physics Girl, Youtube channel

[6] https://www.physicscentral.com/explore/sots/, Science off the Sphere, Physics Central website

[7] https://www.aps.org/programs/outreach/guide/road/index.cfm, Physics on the Road guide, American Physical Society.

[8] D. R. Sokoloff and R.K. Thornton, Using interactive lecture demonstrations to create an active learning environment. The Physics Teacher 35, 340 (1997).

[9] W. M. Roth, C.J. McRobbie, B. K. Lucas, and S. Boutonne, Why may students fail to learn from demonstrations? A social practice perspective on learning in physics. Journal of Research in Science Teaching: The Official Journal of the National Association for Research in Science Teaching, 34(5), 509-533 (1997).

[10] M. D. Sharma, I. D. Johnston, H. Johnston, K. Varvell, G. Robertson, A. Hopkins, C. Stewart, I. Cooper, and R. Thornton. Use of interactive lecture demonstrations: A ten year study. Physical Review Special Topics-Physics Education Research 6 (2), 020119 (2010).

[11] C. Crouch, A. P. Fagen, J. P. Callan, and E. Mazur, Classroom demonstrations: Learning tools or entertainment?. American Journal of Physics 72, 835 (2004).

[12] K. Miller, N. Lasry, K. Chu, and E. Mazur, Role of physics lecture demonstrations in conceptual learning. Physical review special topics-physics education research, 9(2), 020113 (2013).

[13] C. M. Saviz and S. Shakerin, Serious Fun: Using Toys to Demonstrate Fluid Mechanics Principles. The Physics Teacher 52, 332 (2014).

[14] J. Dewey, Art as Experience. New York, NY: Minton, Balch and Co. (1934).

[15] J. Dewey, Democracy and Education. Echo Library (1916).

[16] K. J. Pugh, Transformative experience: An integrative construct in the spirit of Deweyan pragmatism. Educational Psychologist, 46(2), 107-121 (2011).

[17] B. Heddy and K. Pugh, Bigger is not always better: Should educators aim for big transformative learning events or small transformative experiences?. Journal of Transformative Learning, 3(1), 52-58 (2015).

[18] B. W. Frank and L. J. Atkins, Adapting Transformative Experience Surveys to Undergraduate Physics. In AIP PERC Conference Proceedings (2013).

[19] S. Davies, M.K. Halpern, M. Horst, D. Kirby, and B. Lewenstein, Science stories as culture: experience, identity, narrative and emotion in public communication of science. Journal of Science Communication (forthcoming).

[20] M. Halpern, Science Communication as Experience. Presentation at Public Communication of Science and Technology
2018, Dunedin, NZ (2018).

[21] C. Geertz, Interpretation of Cultures. NY: Basic Books (1973). 